\title{
Reconstruction of Small to Moderate Size Peri-Auricular Skin Defects Using Hatchet Flaps
}

\author{
RIHAM LASHIN, M.D. and AHMED ELSHAHAT, M.D. \\ The Department of Plastic Surgery, Faculty of Medicine, Ain Shams University, Cairo, Egypt
}

\begin{abstract}
Background: Peri-auricular region is a special anatomical area including the sideburn area anteriorly, hair superiorly, the non-hairy post-auricular sulcus posteriorly, and the mandibular angle and neck inferiorly. Reconstruction of defects affecting this area should consider all these structures so that hairy area has to be reconstructed with hairy flaps and the non-hairy area has to be reconstructed with non-hairy flaps. Local flaps in the form of hatchet type flap provide this reconstruction aim. The Hatchet flap is a well-known flap used to cover round defects with primary closure of the donor sites in a V-Y fashion.
\end{abstract}

Methods: Hatchet flaps have been used in reconstruction of defects in variable anatomical sites as published by the senior author and proved to be a reliable flap providing stable coverage of the defect by a skin flap from the adjacent area and thus having similar color, texture, and sensation to the lost skin.

Aim of Work: To describe how to utilize the hatchet flap for reconstruction of small to moderate size peri-auricular skin defects in order to provide satisfactory coverage, with the best aesthetic outcome, inconspicuous scars in both the donor and recipient areas, with the least possible complications. Nine cases were presented in this study.

Results: Results were good, all defects were successfully covered. The flaps survived completely, the likeness of hair color and density in the sideburn area was achieved, and the scars at the donor site were hidden in the post-auricular hairline, post-auricular sulcus were maintained and not obliterated by the flap in any of these cases. All patients were shown a satisfactory appearance, with no complications both on the recipient and donor sites.

Conclusion: Hatchet flaps are a versatile and reliable technique for reconstruction of small to moderate size periauricular skin defects which provides a stable coverage of the defect, with safe vascularity of flaps, and provide an excellent cosmetic outcome.

Key Words: Reconstruction - Peri-auricular - Skin defects - Hatchet flaps.
INTRODUCTION

Peri-auricular region or the area surrounding the external ear is a special anatomical area including the sideburn area anteriorly, temporal hair superiorly, the non-hairy post-auricular sulcus posteriorly, and the mandibular angle and neck inferiorly. Reconstruction of defects affecting this area should consider all these structures so that hairy area ex. sideburn and temporal hair area has to be reconstructed with hairy flaps and the nonhairy area ex. post-auricular sulcus, neck area has to be reconstructed with non-hairy flaps.

The sideburn is an important feature of the facial profile in both women and men. Sideburn reconstruction is challenging because of the difficulty involved in acquiring high-quality tissue and achieving proper hair direction for a satisfactory appearance. Scars in the area around the ear and temple are difficult to conceal, so reconstruction of this area is an especially challenging procedure for plastic surgeons [1].

Although these defects, especially those including loss of the sideburn and temporal scalp with subsequent alopecia is relatively frequent as a consequence of traumatic, surgical, and iatrogenic processes, not many techniques of reconstruction have been reported [2].

Of these techniques used for reconstruction of periauricularand sideburn defectsare thepostauricular transposition flap for reconstruction of preauricular defects [3], the expanded temporo-parietooccipital scalp flap [1], the two-stage techniqueusing expanded supra-auricular trapezoidal flap to correct the long-sideburns when there is an associated temporal alopecic defect [2], and thearterial V-Y hair-bearing scalp flap [4], these were examples 
for flaps which provide hairy skin coverage for sideburn reconstruction.

Postauricular skin defects are caused by tumorigenesis, trauma, and infection. Reconstruction of the postauricular surface in an aesthetic manner is a challenge. An ideal flap for the repair of postauricular skin should be thin and flexible, match the recipient site in color, and do not have a donor-site scar [5]. Therefore, a proximal flap should be the first choice [6,7]. Retroauricular artery perforator-based island flaps are considered practical regional flaps for repairing defects of the postauricular and temporal area [6,7], also the use of preauricular flaps [8] and posterior neck rotation flaps [9-11] have been reported to reconstruct a postauricular defects.

Cervicofacial rotation flaps or other local flaps are well established flaps that have been used for decades. They provide excellent tissue for repair of small or periauricular cutaneous defects [12-16]. Other techniques used for reconstruction of large periauricular defects arefree flaps which used for reconstruction of large periauricular defects with exposed lateral temporal bone ex. radial forearm free flaps, anterolateral thigh flap, and rectus abdominis free flaps, these flaps carry the disadvantage of being non-hairy, the donor site morbidity, in addition to the long operative time and complex surgery [17].

Among the techniques used in reconstruction of such defects are the sequential tissue expansion of the scalp which have been used for reconstruction of large lateral scalp defects ex. Post burn reconstruction $[\mathbf{1 8 , 1 9 ]}$. This technique has the advantage of providing hairy flaps, but has the disadvantage of the multiple stages needed to cover the defect, the frequent fellow up visits to inject the expander, in addition to the expander related complications [18-20].

Local flaps are aesthetically and functionally more advantageous in reconstructions than are free flaps or skin grafts. Local flaps in the form of hatchet type flap provide this reconstruction aim as well [21].

Hatchet flap is basically a V-Y rotation advancement flap, with incomplete incision at one limb of the V. This provided a skin pedicle in addition to the subcutaneous pedicle. Hatchet flap designed by conversion of the elliptical excision usually used to excise a round defect, into two flaps leaving portion of skin attached, to act as a pedicle for each flap, with primary closure of the donor site [21,22].
Hatchet flaps have been used in reconstruction of defects in almost all regions of the body as published by the senior author, and proved to be a reliable flap providing stable coverage of defects by a skin flap from the adjacent area, and thus having similar color, texture, and sensation to the lost skin [21].

\section{Aim of work:}

The aim of this article is to describe how to utilize the hatchet flap for reconstruction of small to moderate peri-auricular skin defects in order to provide satisfactory coverage, with the best aesthetic outcome, inconspicuous scars in both the donor and recipient areas, with the least possible complications.

\section{PATIENTS AND METHODS}

Nine patients were presented in this study, all of them underwent reconstruction of defects in the peri-auricular region using hatchet flaps from August 2015 to August 2016. Thirteen hatchet flaps were used to reconstruct nine peri-auricular defects in nine patients (one hatchet flap used to cover defect in 5 patients, and 2 hatchet flaps used in 4 patient). The youngest patient was 7 years old and the oldest was 65 years old.Six patient were males and three were females. The causes of defects were traumatic defects, defects after benign or malignanttumor excision, defects after nevus sebaceous of Jadassohn, and pigmented lesions excision. All patients were operated by the senior author. All patients underwent the surgery under general anesthesia. Mean follow-up period was 6 months. Informed consent for the procedure was obtained from all patients preoperatively.

\section{Surgical technique:}

The design of a hatchet flap was marked preoperatively by drawing a V-shaped marking where one limb of the V started at the round defect and the other limb stopped before reaching the defect (Figs. 1b,2b,3b,5a). The length of thisunmarked segment (the skin pedicle of the flap) was almosthalf the base of the triangle (the defect diameter). The length of this unmarked segment depended on whether the flap has axial or random pattern of circulation and whether a subcutaneous pedicle was left or not. The orientation of the triangle was judged by the choice of the flap and by thedirection that allowed closure of the donor site with the minimal possible tension [21].

After excision of the tumor with safety margin incases of basal cell carcinoma and parotid tumors; debridement of post-traumaticwounds; and excision 
of pigmented lesions and nevus sebaceous of Jadassohn, the defects were covered by the preplanned hatchet flaps. All patients underwent the surgery under general anesthesia.

The hatchet flaps were classified in previous study by the senior author into type I and type II hatchet flaps. Type I hatchet flaps were left attached to the deeper subcutaneous tissues, fascia, or muscle and advanced by using the natural viscoelasticity and stretching of tissues. These provided double blood supply to type I hatchet flaps, one from the deeper perforators and the second from the skin attachment (Figs. 3,5) [21].

Type II hatchet flaps were undermined and elevated from the underlying tissues. The planes for undermining were the subgaleal, supraplatysmal, or subfascial planes. Therefore, they depended on single source of blood supply from the site of skin attachment. This undermining allowed greater distance of rotation advancement of the flap (Figs. $1,2,4)[21]$

The advancement of the hatchet flap type I is limited by its deep connections and therefore used to cover small defects. Type II hatchet flap can be advanced for a longer distance [21,23].

In this current study, patient with pigmented lesion was reconstructed with type I hatchet flap, otherwise patients are reconstructed with type II hatchet flaps.

Care was taken to cut parallel to the hair follicles and to ensure that dissection of the flap did not remove follicles from the subcutaneous tissue.

The donor sites of the flaps in all cases were primarily closed in V-Y fashion. Different degrees of undermining of the skin at donor sites were

done to allow easy closure without tension. Excessive tension was noted in two patients while closing the donor site at the junction of the $\mathrm{V}-\mathrm{Y}$ advancement, and a Z-plasty was added to release tension of the donor areas. This Z-plasty modification was quoted from Hayashi et al., 1998 [24] study. Suction drains were applied in all cases. Figs. $(1 \mathrm{c}, 2 \mathrm{c}, 3 \mathrm{c}$, $4 \mathrm{e}, 5 \mathrm{~b})$ show inset of the flaps and closure of the donor sites.

\section{RESULTS}

Results were good, the hatchet flaps successfully covered all defects. The intra-operative blood loss during elevation of flaps was very minimal, and the duration of surgery was short. All patients discharged on the $2^{\text {nd }}$ postoperative day. Postoperative period for all patients including those with co-morbidities (hypertension, diabetes mellitus, etc.) was uneventful.

Both the hatchet types I and II flaps survived completely, the likeness of hair color and density in the sideburn area was achieved, and the scars at the donor site were hidden in the post-auricular hairline, post-auricular sulcus were maintained and not obliterated by the flap in any of these cases.

Donor sites were closed primarily, with no need for skin grafting. No wound dehiscence or scar hypertrophy occurred, and no secondary procedures performed in any of our patients.

All patients were shown a satisfactory appearance, with no complications both on the recipient and donor sites. The mean followed-up period was 6 months with persistence of stable coverage.

Figs. (1c, 2c, 3c, 4e, 5b) show the postoperative results.
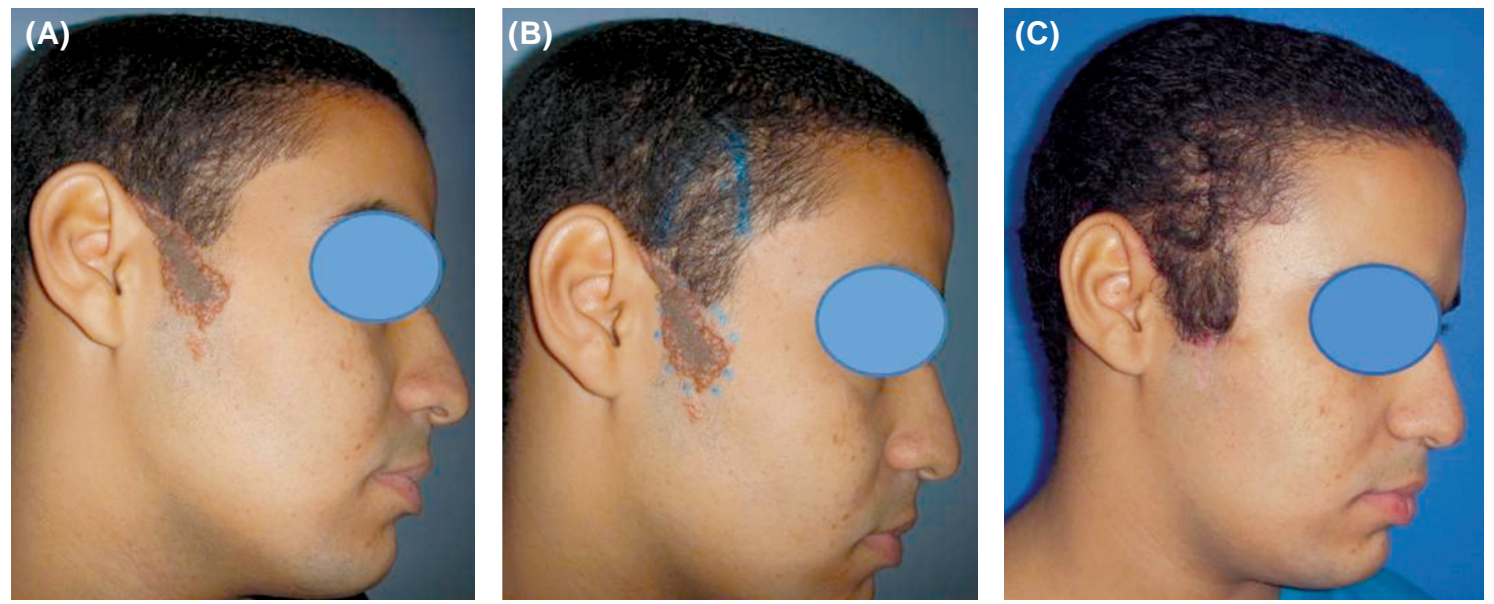

Fig. (1): (A) Preoperative photo for a 22 years old, male patient with nevus sebaceous of Jadassohn involving the right sideburn area. (B) Marking of a hatchet flap at the hairy scalp adjacent to the lesion. (C) One month postoperative photo show complete survival of the flap, with complete healing of both the flap and the donor site (Type II). 

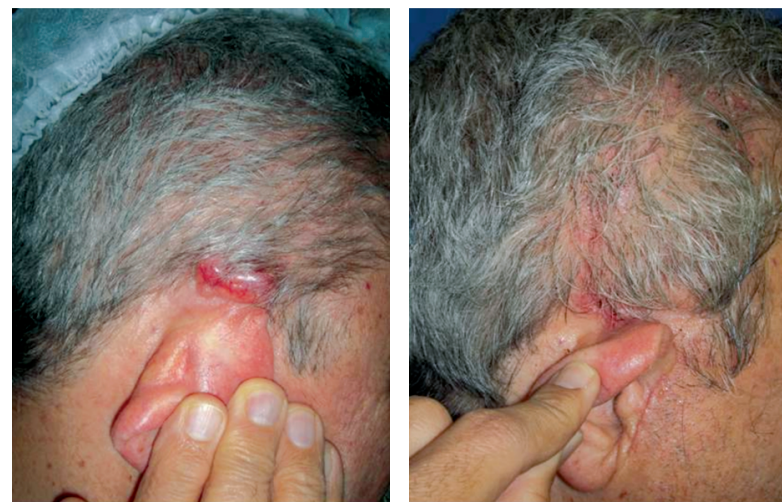

(A)

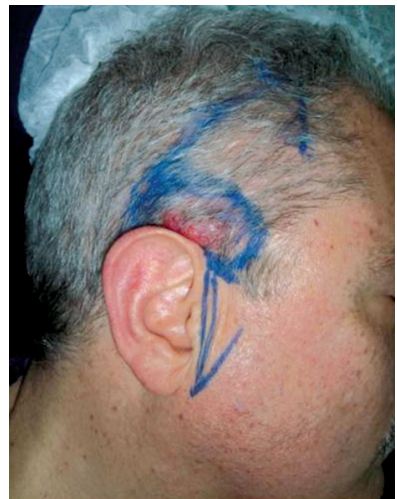

(B)

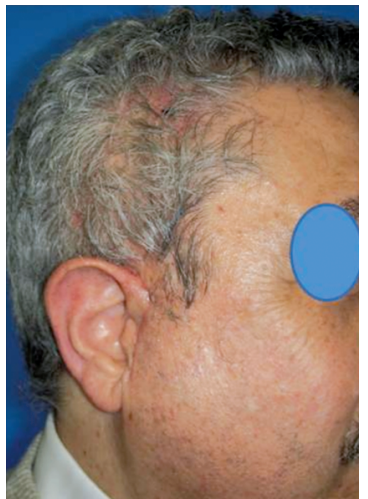

(C)

Fig. (2): (A) Preoperative photo for a 60 years old, male patient, presented with BCC involving the right peri-auricular region posterio-superiorly. (B) Marking for two hatchet flaps is shown. (C) One month post-operative photo for the patient show complete healing of the flaps and donor site, with inconspicuous scars in both donor and recipient sites (Type II).
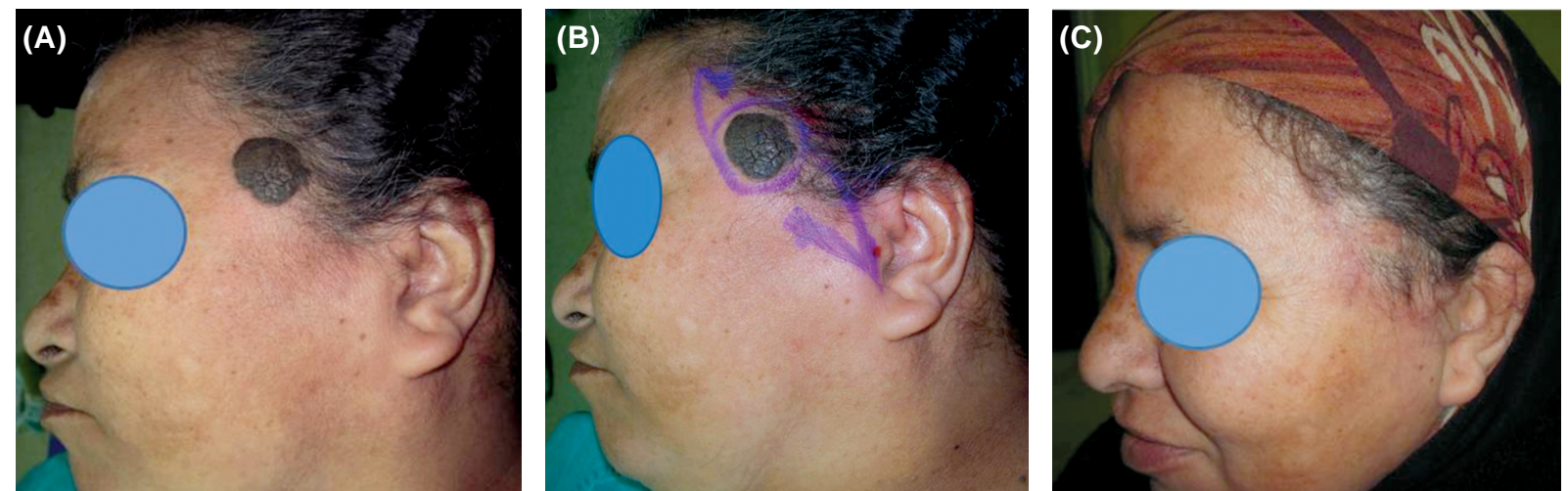

Fig. (3): (A) Preoperative photo for a 45 years old, female patient with benign pigmented lesion on the area just superior to the sideburn. (B) Marking of double opposing hatchet flaps. (C) One month postoperative photo for the same patient, show complete healing of the flap and donor site (Type I).
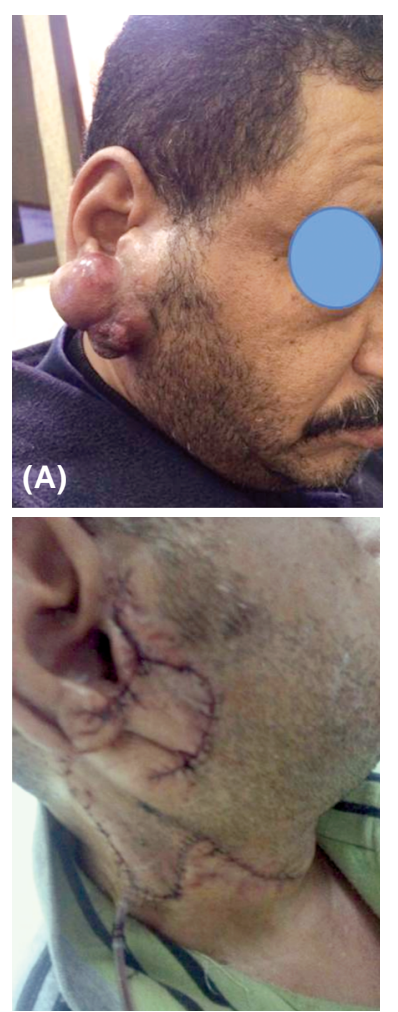
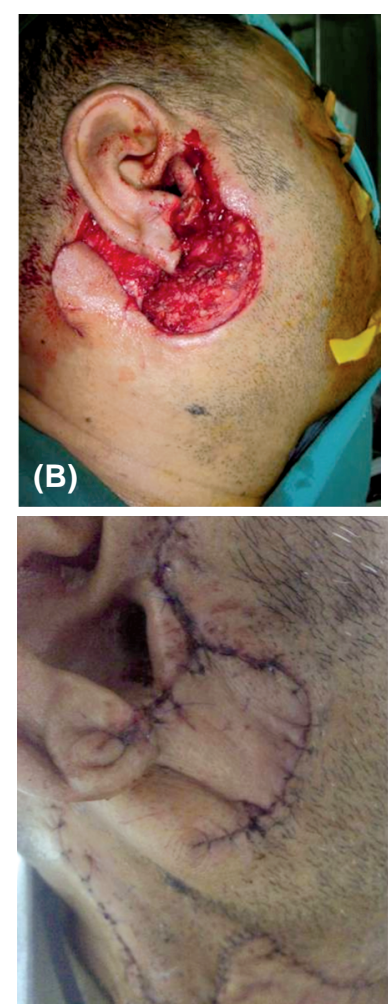

(E)
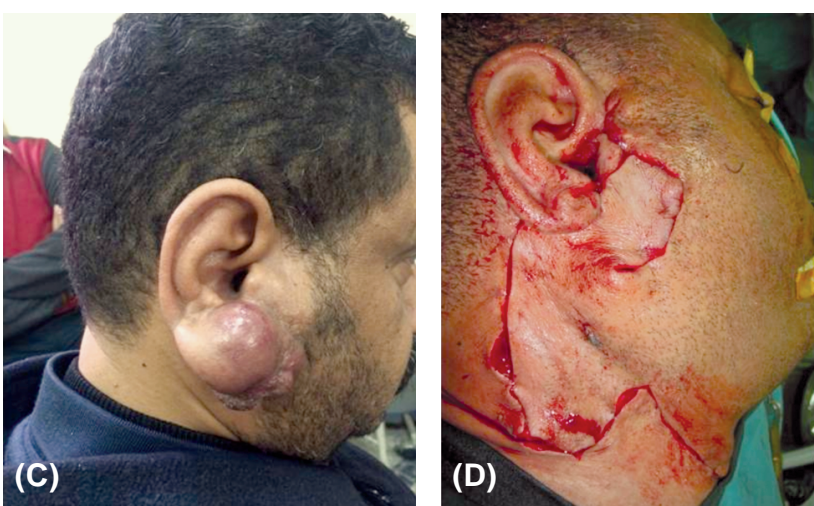

Fig. (4): (A) Preoperative photo of a 40 years old, male patient, with malignant lesion affecting the skin over the parotid area and over the ear lobule (high grade salivary duct carcinoma). (B) Intraoperative photo after excision of the peri-auricular tumor with good safety margin. (C) Preoperative photo for the patient. (D) Intraoperative photo show transposition and in-setting of the hatchet flap (Type II) after excision of the tumor, and direct closure of the donor site. (E) 2 weeks postoperative photo for the same patient show complete survival of the flap and complete healing for both the flap and the donor site. 

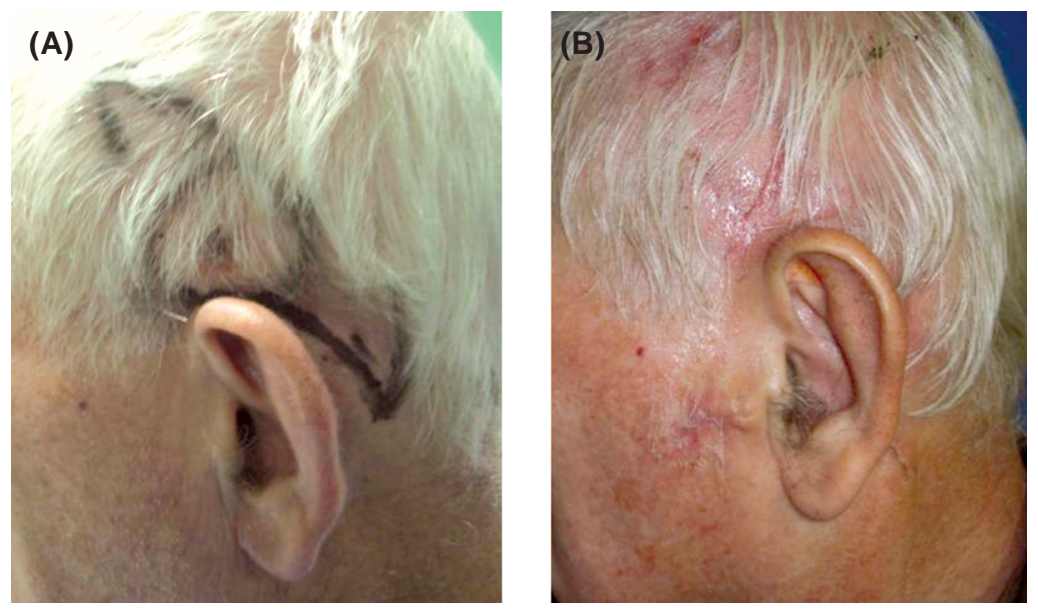

Fig. (5): (A) Preoperative photo for a 62 years old male patient, with BCC affecting the left periauricular area postro-superiourly, with marking of 2 hatchet flaps. (B) One month postoperative photo for the same patient show complete healing for both the flap and the donor site (Type I).

\section{DISCUSSION}

The best option for reconstruction of any defect is the local flap technique. Gillies and Millard [25] wrote that "the next best skin is the next nearest skin". It provides skin that is optimal match in terms of skin color, texture, and sensation. Traditional options for reconstruction of periauricular defects include the use of cervicofacial rotational flaps, split thickness skin grafting, and regional pedicled flaps [17].

Emmett [26] was the first to describe the hatchet flap in 1977, and thenhatchet flap was described in facial reconstruction [27-33], pressure sore reconstruction [23,34-37], lumbosacral meningomyelocele reconstruction [38], and fingertip amputation reconstruction [39].

Among the previous techniques used to reconstruct the sideburn area was the expanded temporoparieto-occipital scalp flap, which results in satisfactory hair density and direction, inconspicuous scars in both the donor and recipient areas [1]. However the blood loss and length of surgery is much more than that of local hatchet flaps described in the current study.

A two-stage technique to correct the longsideburns when there is an associated temporal alopecic defect by means of an expanded supraauricular trapezoidal flap achieved also a satisfactory appearance of the sideburn [2], however being two stage procedure doesn't make it the 1 st option in peri-auricular and sideburn defects reconstruction.

Nine patients were included in the current study which is comparable to another study by Hayashiet al., 2015 in which the authors described their experiencewith reconstruction using a flapmethod for eight patientswith missing tissue in the cheek and preauricularregion [40]. But in a higher age group starting from 17-88 years old. The preauricular defects were larger in size than in the current study and including the cheek area because all of the cases were defects due to malignant tumor excision. They used the malar-posterior auricularcervico flapbased on the concept of separately designing the flap with the 3 areas comprising the malar, posterior auricular, and cervical regions [40].

The disadvantage of this technique is the use of skin graft to cover the donor area the posterior auricular and clavicular tissue defects that arose after movement of the flap, hematoma, and hypertrophic scar in the posterior auricular area [40]. In the current study all donor sites closed primary and we didn't use skin grafts in any of our cases.

Among the flaps described to reconstruct a postauricular defect is the use of theretroauricular artery perforator flapdescribed by Zhang et al., 2016 [5]. In their study on a larger group of patients including fourteen patients with postauricular defects in a higher age group ranged from 55 to 75 years who underwent reconstruction using the retroauricular artery perforator flap [5].

This technique necessitate the use of ultrasound Doppler blood flow detection preoperatively, and the flap needs magnification loupe and meticulous dissection to avoid traumatizing, stretching, or kinking the perforator artery as the vessel is easily traumatized by perforator dissection. Another major disadvantage for this flap isthe venous congestion which occurred in the early postoperative period 
[5]. In hatchet flap technique, it is technically easy, with no need for preoperative imaging or use of magnification loupe to elevate the flap, in addition that we didn't experience any venous congestion in any of our study cases.

Free flaps have been shown to provide the best tissue for reconstructions of large periauriculardefects with lateral temporal bone defects after surgical ablation of cutaneous tumors. These composite soft tissue defects are best reconstructed with composite tissue. A retrospective study by Rosenthal et al., 2008 [17] included 73 patients with ages ranging from 38 to 83 years, who had periauricular defects requiring 74 free tissue transfers. Their study include larger number of patients, longer fellow-up period (median, 15 months), and larger defects than the current study. Early on, reconstruction was performed using a radial forearm (RFFF), evolving to lateral arm, rectus, and finally an anterolateral thigh (ALT) freeflap. Periauriculardefects were classified based on preservation of the external auditory canal (class I), lateral temporal bone resection with preservation of the auricle (class II), or lateral temporal bone with total auriculectomy (class III) [17].

Class I defects were best managed by RFFF reconstruction, class II defects were managed well with the ALT flap, and class III defects required the ALT or rectus flap [17].

The free tissue transfer carry the risk of total or partial flap loss, excessive bulk which require secondary debulking, wound healing problems, poor color match, provide non-hairy tissue, lengthy surgery with possibility of blood loss, the complexity of surgery, longer hospital stay, in addition to the donor site morbidity. However, when large composite defects are encountered, free tissue transfer may be the only option.

Tissue expansion is the most important armamentarium for aesthetic hair bearing scalp reconstruction [18-20]. Most commonly used to treat cases with post-burn and post-traumatic defects. Aesthetic reconstruction of large periauricular defects with alopecic temporal hair and sideburn reconstruction with sequential tissue expansion have been discussed previously in literature [1820]. In a study by Gurlek et al., [18] included 12 patients with a mean age of 20 years, who underwent sequential tissue expansion to reconstruct large periauricular defects with alopecic temporal hair and sideburn, showed that tissue expansion is safe and efficient technique in providing hairy flaps, but time consuming, needs multiple stages to cover the defect, taking into considerations the expander related complications [18-20].

In the current study, the hatchet flaps successfully covered all defects. The intra-operative blood loss during elevation of flaps was very minimal, and the duration of surgery was short in comparison to other techniques, and donor sites were closed primarily, excellent cosmetic appearance was achieved, which give this flap a great advantage and can consider it as a 1st option in reconstructing different small to moderate size periauricularskin defects. However limitation to this technique includes large periauricular defects and composite defects which usually encountered after radical resection of large malignant skin lesions in this area, and the only option in such case is free tissue transfer.

\section{Conclusion:}

Hatchet flaps are a versatile and reliable technique for reconstruction of small to moderate size peri-auricular skin defects. They provide a stable flap coverage of the defect, with safe vascularity of flaps. The cosmetic appearance is excellent due to the use of skin just adjacent to the defect. Careful positioning of incisions facilitates closure without tension and produces inconspicuous scars. Short operating time and minimal blood loss make these flaps suitable for patients with co-morbidities. It is limited to small to moderate size skin defects, while larger or composite defects needs more complex reconstruction with free tissue transfer.

\section{REFERENCES}

1- Yang Z., Fan J., Tian J., Liu L., Gan C., Chen W. and Yin Z.J.: Aesthetic Sideburn Reconstruction with an Expanded Reversed Temporoparieto-occipital Scalp Flap. Craniofac. Surg. Jul., 25 (4): 1168, 2014.

2- Giraldo F., Gonzalez C., Garnica I., Ferron M. and Rus J.A.: Sideburn Reconstruction with an Expanded Supraauricular Trapezoidal Flap. Plastreconstr Surg. Jul., 100 (1): 257, 1997.

3- Sedwick J.D. and Langdoc C.J.: Postauricular Transposition Flap for Cutaneous Auricular Defects. Arch. Facial Plast. Surg., 7 (6): 418, 2005.

4- Davis W.H.: Sideburn Reconstruction with an Arterial VY Hair-bearing Scalp Flap after the Excision of Basal Cell Carcinoma. Plast. Reconstr. Surg. Jul., 106 (1): 94, 2000.

5- Zhang Y.Z., Li Y.L., Yang C., Fang S., Fan H. and Xing $X .:$ Reconstruction of the Postauricular Defects Using Retroauricular Artery Perforator-Based Island Flaps. Anatomical Study and Clinical Report. Medicine, 95: 37: $1,2016$.

6- Youn S., Kim Y.H., Kim J.T., et al.: Successful Reconstruction of a Large Helical Rim Defect Using Retroau- 
ricular Artery Perforator-Based Island Flap. J. Craniofac. Surg., 22: 635, 2011.

7- Cordova A., D’Arpa S., Pirrello R., et al.: RetroauricularSkin: A Flaps Bank for Ear Reconstruction. J. Plast. Reconstr. Aesthet. Surg., 61(Suppl 1): S44, 2008.

8- de Almeida O.M. and Gemperli R.: Reconstruction of a Postauricular Defect Using a Preauricular Flap. Dermatol. Surg. Jul., 36 (7): 1191, 2010.

9- Thomaidis V.K.: Cutaneous Flaps in Head and Neck Reconstruction: From Anatomy to Surgery. Online Book. Published by Spriger-Verlag Gambh. Berlin, (6): 84, April 2014.

10- Stark R.B. and Kaplan J.: Rotation Flaps Neck to Cheek. Plast. Reconstr. Surg., 50: 230, 1972.

11- Crow M.L. and Crow J.: Resurfacing Large Cheek Defects with Rotation Flaps From the Neck. Plast. Reconstr. Surg., 58: 196, 1976.

12- Moore B.A., Wine T. and Netterville J.L.: Cervicofacial and Cervicothoracic Rotation Flaps in Head and Neck Reconstruction. Head Neck, 27: 1092, 2005.

13- Kaplan I. and Goldwyn R.M.: The Versatility of the Laterally Based Cervicofacial Flap. Plast. Reconstr. Surg., 61: 390, 1978.

14- Juri J. and Juri C.: Advancement and Rotation of Large Cervicofacial Flaps for Cheek Reconstruction. Plast. Reconstr. Surg., 64: 692, 1979.

15- Becker D.W. Jr.: A Cervicopectoral Rotation Flap for Cheek Coverage. Plast. Reconstr. Surg., 61: 868, 1978.

16- Bokhari W.A. and Wang S.J.: Modified Approach to the Cervicofacial Rotation Flap in Head and Neck Reconstruction. The Open Otorhinolaryngol. J., 5: 18, 2011.

17- Rosenthal E.L., King T., McGrew B.M., Carroll W., Magnuson J.S. and Wax M.K.: Evolution of a Paradigm for Free Tissue Transfer Reconstruction of Lateral Temporal Bone Defects. Head \& Neck, 5: 589, 2008.

18- Gurlek A., Alaybeyoglu N., Demir C.Y., Aydogan H., Bilen B.T. and Aezturk A.: Aesthetic Reconstruction of Large Scalp Defects by Sequential Tissue Expansion Without Interval. Aesth. Plast. Surg., 28: 245, 2004.

19- Guzey S., Alhan D., Sahin I., Aykan A., Eski M. and Nisanci M.: Our Experience on the Reconstruction of Lateral Scalp Burn Alopecia with Tissue Expander. Burns J., 41: 631, 2014.

20- LoGiudice J. and Gosain A.K.: Clinical Overview: Pediatric Tissue Expansion: Indications and Complications. Jr. Craniofacial Surg., 14: 866, 2003.

21- Elshahat A.: The Versatility of the Hatchet Flap in Soft Tissue Reconstruction and a Proposed New Classification. Eur. J. Plast. Surg., 35: 351, 2012.

22- Jackson I.T.: Forehead Reconstruction. In: Jackson I.T. (ed) Local flaps in Head and Neck Reconstruction, 2nd edn. Quality Medical, St. Louis, pp 47-100, 2007.

23- Josvay J., Sashegyi M., Kelemen P. and Donath A.: Modified Tensor Fascia Lata Musculofasciocutaneous
Flap for the Coverage of Trochanteric Pressure Sores. J. Plast. Reconstr. Aesthet. Surg., 59: 137, 2006.

24- Hayashi A., Maruyama Y., Saze M. and Okada E.: The lateral Thigh V-Y Flap for Repair of Ischial Defects. Br. J. Plast. Surg., 51: 113, 1998.

25- Gillies H.D. and Millard D.R.: The Principles and Art of Plastic Surgery. 2 vols. Little, Brown \& Co, Boston, 1957.

26- Emmett A.J.: The Closure of Defects by Using Adjacent Triangular Flaps With Subcutaneous Pedicles. Plast. Reconstr. Surg., 59: 45, 1977.

27- Reynaud J.P.: Hatchet Flap for the Repair of Cutaneous Excisions on the Nose. Ann. Chir. Plast. Esthet., 28: 369, 1983.

28- Horwath H., Roscic I., Falkensammer G. and Engleder R.: Hatchet-Form Flap as a Method of Aesthetic Reconstruction of the Nose. Fortchr Kiefer Gesichtschir, 34: $151,1989$.

29- Baron J.L., Reynaud J.P., Gary-Bobo A. and Maya M.: Specificity of Hatchet Flaps in the Laterofacial Region. Ann. Chir. Plast. Esthet., 35: 47, 1990.

30- Tremblay J.F. and Bernestein S.C.: Hatchet Flap. Dermatol. Surg., 27: 1049, 2001.

31- Pan Y., Ai Y., Li H. and Guo S.: Local Hatchet Flap for Facial Skin Defects Reconstruction in Special Areas. Dermatol. Surg., 30: 1256, 2004.

32- Gargano F. and Alfano C.: Versatility of the Hatchet Flap in Facial Reconstruction. Acta. Chir. Plast., 47: 67, 2005.

33- Yu T.C., Desciak E.B. and Eliezri Y.D.: Bilateral Hatchet Flaps. Dermatol Surg. (32):1279, 2006.

34- Quillot M., Lodde J.P., Pegorier O., Reynaud J.P. and Cormerais A.: A Variant of Island Flaps for the Covering of Pressure Sores: The Hatchet Flap: A Props of 31 Cases. Ann. Chir. Plast. Esthet., 39: 469, 1994.

35- Josvay J. and Donath A.: Modified Hamstring Musculocutaneous Flap for The Coverage of Ischial Pressure Sores. Plast. Reconstr. Surg., 103: 1715, 1999.

36- Demirseren M.E., Gokrem S., Ozdemir O.M., Katircioglu A., Can Z. and Serel S.: Hatchet-Shaped Tensor Fasciae Latae Musculocutaneous Flap for the Coverage of Trochanteric Pressure Sores: A New Modification. Ann. Plast. Surg., 51: 419, 2003.

37- Schwabegger A.H., Delfrari B. and Apprich C.: PedicledDeltoid Hatchet Flap for Treatment of Pressure Sore at the Shoulder. Eur. J. Plast. Surg., 28: 534, 2006.

38- Josvay J. and Bognar L.: Large Lumbosacral Meningomyelocele Closure with Gluteus Maximus Musculocutaneous Hatchet Flap. Eur. J. Plast. Surg., 25: 378, 2003.

39- Tuncali D., Barutcu A.Y., Gokrem S., Terzioglu A. and Aslan G.: The Hatchet Flap for Reconstruction of Fingertip Amputations. Plast. Reconstr. Surg., 117: 1933, 2006.

40- Hayashi T., Yamamoto Y., Oyama A., Funayama E., Shichinohe R., Murao N. and Furukawa H.: Reconstruction of Large Cheek Defect With/Without Sideburn Using Malar-Posterior Auricular-Cervico Flap. Ann. of Plast. Surg., 77 (2): 137, 2016. 